\title{
How Social Media Can Afford Engagement Processes
}

\author{
Xiaoxiao Zeng ${ }^{1}$, Brad McKenna ${ }^{1}$, Shahper Richter ${ }^{2}$, Wenjie $\mathrm{Cai}^{3}$ \\ ${ }^{1}$ University of East Anglia, Norwich, United Kingdom \\ \{xiaoxiao.zeng, b.mckenna\} @uea.ac.uk \\ 2 Auckland University of Technology, Auckland, New Zealand \\ shahper.richtereaut.ac.nz \\ ${ }^{3}$ University of Greenwich, London, United Kingdom \\ w.cailgreenwich.ac.uk
}

\begin{abstract}
The increasing popularity of social media has led many organizations to find new ways of customer engagement. This paper presents an initial pilot study to explore the affordance of social media in engagement processes. By applying the affordance theory and Porter's process for engagement model, we used a case study approach to examine the case company's Facebook and Twitter content to identify the engagement possibilities of social media. Our preliminary results show that social media opens a new channel for organisations to engage with their customers. We present a preliminary theoretical model to understand the how the functional affordances of social media are socialised in engagement processes, which ultimately gives rise to socialised affordances.
\end{abstract}

Keywords: Social media. Engagement. Functional affordances. Socialised affordances

\section{Introduction}

The utilization of social media has generated a considerable body of research in the last decades. For example, social media and engagement [1,2], social media and electronic word of mouth [3], social media and branding [4]. Social media represents a significant innovation for customer engagement, it allows information changes among customers and influences potential customer decisions [5]. Social media has changed the way companies communicate with customers, hence, allowing companies to organize a variety of customer engagement strategies [6]. Social media is important for customer engagement, yet our understanding remains limited. Although there exists a wide range of research in social media and customer engagement [7-9], none of this research explores how the features of social media afford engagement processes. Therefore, there is need for researchers to investigate how social media can afford the customer engagement. This study aims address the gap by using "Affordances" theory [10]. To explore the possibilities of social media in the engagement process, we drew up the following question: How do affordances of social media tools facilitate the customer engagement process?

\section{Social Media and Customer Engagement}

Many scholars have examined brands and customer relationships on social media [1114]. Gensler, Völckner [4] say that social media enable dynamic and real-time interaction between company and customer, while this new change also lets brand 
managers lose control of their brand. Hence, social media is a double-edged sword, it is important for brand managers to understand customer needs and cope with customer issues in this new environment.

It is necessary for firms to know how they are using social media applications, specifically, for what content they should post to serve their business objectives [15]. Naaman, Boase [16] examine the characteristics of social activity and pattern of communications on Twitter, called "social awareness streams". Based on their work, Lovejoy and Saxton [17] proposed an "Information-Community-Action" microblog message classification in organizational level. Harder, Howard [18] used this classification to build their analysis of "One Book Nova Scotia" activity. They split the tweets into three separate categories: Information, which represents information functions, like offer news, highlights; Conversation, which provides direct interaction with the community, for example, @ participants or direct conversations; Actionorientation, which engages followers to participate in something, such as events.

\section{Theoretical Framework}

Affordances represent the concept of "action possibilities" as perceived by the environment [10]. The existence of affordances is when opportunity for action is available and affordances are properties of the relationship between an object and a social entity [19]. Therefore, when applying affordance to technology, the interaction of animal \& environment would be replaced by human \& artefact [20]. Affordance theory has been applied by some scholars to understand the relationship between technological artefacts and organizations, and how technology creates possible interactions that affect organizations [21-23]. Leonardi [22] argues that technology affordances are usually the same or similar across different organizational environments because the material characteristics or features of the technology limit people's use of it. Majchrzak and Lynne Markus [24] interpret technology affordances use in information systems as "an action potential, that is, to what an individual or organization with a particular purpose can do with a technology or information system" (p.832).

Treem and Leonardi [23] explore social media use in organizations, they identified the affordances of Visibility, Editability, Persistence, and Association. The affordance of persistence allows for growing content, sustaining knowledge and communication over time. The editability of social media affords more purposeful communication, this means the asynchronous text-based conversation gives users the time to improve information quality, targeting content and regulating personal expressions. The affordance of association allows individuals to connect with others or content, it supports social connections and enables relevant or emergent connection.

\section{Methodology}

\subsection{Case Study - The Dairy}

Our case study is a dairy farm (hereafter referred to as The Dairy) in the south west region of the United Kingdom, which produces milk, cream, butter and yoghurt. The Dairy aims to build brand awareness and engage more with its customers. The Dairy has three core customer groups: national retailers (49\%), local independent businesses $(30 \%)$ and local dairy ingredients to food manufacturers $(21 \%)$.

\subsection{Data Collection}

Data was collected through Facebook and Twitter. For triangulation purposes of social media data [25], we also used additional data collected from the case company's website. We used Netlytic to collect primary data from public tweets by using the search criteria of relevant hashtags (not named here due to anonymity), and The Dairy's Twitter handle posts between 26 June 2017 and 26 July 2017. We also downloaded posts from The Dairy's Facebook page. Posts were collected using R by 
using the same search criteria we used for Twitter. We gathered 1712 posts consisting of 4 events, 62 videos, 111 text status updates, 334 links, and 1215 photos.

\subsection{Data Analysis}

We used text analysis to investigate how The Dairy promotes participation through social media activities. Text analysis results are analysed through coding form in Excel. We also analysed data from the company's website. This helped us to understand The Dairy's brand-expression and how they successfully transform customers from their website to social media platforms.

\section{$5 \quad$ Preliminary Findings and Discussion}

\subsection{Understanding Customer Needs and Motivations}

It is important for firms to know what their customers expect from them [26]. Porter, Donthu [27] argue that satisfying social and psychological needs motivate customers to participate in various social media platforms. Therefore, the engagement processes model is rooted in the notion that customer engagement is based on the value created when companies or brands help them meet their needs [28]. Social media provide a good way for firms to understand their customers through the Internet. Two socialising affordances in understanding customer needs were derived from the data: embedded social media analysis features and two-way communication.

Embedded social media analysis features. The Dairy applied the embedded features from their social media platforms to help them monitor customers; this validates Treem and Leonardi [23] arguments that social media afford companies visibility to visualize the customer preference and behaviours. The Dairy uses Twitter analytics to help them understand their follower's interests and what types of posts they expect to see. In the past, usually firms analysed customer preferences by sending questionnaires or collect from face-to-face interviews, all of which are inconvenient and time-consuming [29]. These embedded analysis tools make it more convenient for firms to understand customer motivations and preferences.

Two-way communication. The Dairy posts many messages, while at the same time they also receive a lot comments and feedback from customers. It illustrates the functional affordances of persistence and editability [23]. This finding also verifies the change of social media marketing [30, 31]. Indeed, social media affords multi-way communication for firms, which not only enable them talk to customers but also allow customers talk to companies and customers communicate with each other. Firstly, companies can initially ask their audience about their preferences or post questions on social media platforms, which is the traditional way of communication. The Dairy uses Facebook and Twitter to collect large numbers of customer opinions. We found that the company posts a lot messages for gathering opinions about their products and brands.

We've always believed that in life you get out what you put in - and this ethos is no different in our dairy. If you can tell us what you think makes our milk taste so uniquely different and delicious, then you could win a lovely prize!

Get guessing... (Facebook, 2013-05-11)

Secondly, customers also can express their experience and opinions freely and users have more control over the content [32]. The Dairy withdrew several products in August 2014 because there has been an unfortunate error at one of their farms. This incident received lots of negative comments from customers. Some customers expressed their worries or complained about The Dairy. The negative comments damaged The Dairy's image in the public (see below).

Please let us know what the common substance is - it's bad enough that our household has already drank 4 pints and are already a way into a second 4 
pint (both dated 25th Aug). I'm not looking to throw a fit or blame coincidental symptoms of a bug but my toddlers have drunk the milk straight - the environment agency's word is useless without us knowing if we've been drinking bleach, chlorine and more (Facebook, 2014-08-18).

This example demonstrates that social media platforms provide two-way communication for customers and organisations, it not only enables marketing managers to communicate with customers and seek responses in social media network's comments sections, but also allows for customers to communicate freely about the products in public.

\subsection{Promote Participation}

Social media enable firms to engage audiences and generate useful business insights [33]. The Dairy created different types of content and launched different activities on social media. There are three socialising affordances in engagement processes derived from our data: brand-expression, encouraging content creation, and creating enjoyable experiences.

Brand Expression. Social media can be a powerful tool to spread brand-expression and enhance brand awareness [34]. The Dairy's brand-expression is "delicious things" which was developed based on customers' comments. It illustrates the social media affordances of visibility and editability [23]. The Dairy explains that "Delicious things says everything we want to say about the natural goodness, the care, the attention and the expertise you can taste every time you try one of our delicious products". We conclude that customers hold positive views about the products and the brand. People talked a lot about the clotted cream and butter. There are also plenty of descriptive words like "good", "yummy", "fantastic" and "amazing". The Dairy strategically uses customer-generated content to build their brand-expression and show what customers say about their products to the public.

Encourage content creation. As highlighted by Treem and Leonardi [23], social media afford editability which enables more purposeful content creation, the association allows individuals to connect with others through social media functions (e.g., likes/shares), and the affordance of persistency enables the company to grow content. The Dairy encourages content creation through two aspects: firstly, by posting different types of content to involve participants; secondly, encouraging their fans to like or share the content they produce.

Create enjoyable experience. Research shows that people would have favourable attitudes towards a firm, which provides them with enjoyable experiences [27]. The Dairy uses social media to provide a variety of enjoyable experiences to engage its existing customers and potential customers, like competitions and recipes. This finding validates Treem and Leonardi [23]'s statement that social media affords individual editability to craft and compose messages, which can aid to target content and improving content quality. The company launched lots of competitions to increase this involvement.

Competition time! Following on from last years 'How many balloons in a Smart Car' is this years 'How many balloons in a Mini'. Let us know your answers by 4 pm today and you could be in with a chance to win some The Dairy goodies! (Facebook, 2016-02-24)

\subsection{Motivate Cooperation}

Social media affords users the visibility to identify the network connections and the ability of association to support and build social connections [23]. Therefore, identifying influencers and cooperating with them can greatly contribute to higher customer engagement. Harder, Howard [18] suggest managers should engage different types of participants to facilitate the engagement processes. Gruzd and Haythornthwaite [35] add that it is necessary to involve community members into 
social media activities. Hence, two socialising affordances of social media in motivating cooperation were derived from datasets: finding influencers and constructing networks.

Find influencers. It is necessary for organizations to find the influential actors quickly in the network [36]. Li, Lin [8] suggest companies should build interactions and cooperation with influencers. The Dairy builds interactions with some potential influencers to spread brand awareness.

Construct networks. We found that The Dairy has direct connections with wide range of users. We grouped the participants into 3 groups. The first group is dairy related organizations: a local market, a herb farm, a bakery, and a baker. The second group we named other organizations (organizations that do not directly relate to dairy), which contains travel agencies, financial companies, and hotels. The third group are individual users who generally are fans of The Dairy.

\section{Affordance of Social Media in the Engagement Processes}

Our preliminary theoretical model (figure 2) was developed based on the discussion above. The first column is based on Treem and Leonardi [23], and the second on Porter, Donthu [27]. The functional affordances of social media are "socialized" through engagement processes. Social media affords visibility, editability and persistence, which makes it possible for The Dairy to understand customer needs and motivations and promote more participation. The functional affordances of social media should be socialized by human actions. By this, we mean, The Dairy managers need to use Twitter or Facebook and related technologies to carry out a series of activities such as "mentions" find influencers, and establish Facebook groups to support engagement processes.

\begin{tabular}{|c|c|c|c|c|}
\hline \multirow{2}{*}{$\begin{array}{l}\text { Functional } \\
\text { Affordances of } \\
\text { Social Media }\end{array}$} & & \multirow{2}{*}{$\begin{array}{l}\text { Engagement } \\
\text { Processes }\end{array}$} & \multirow[b]{3}{*}{ Give rise to } & Socializing Affordances \\
\hline & & & & \multirow{2}{*}{$\begin{array}{l}>\text { Embedded social media } \\
\text { analysis features } \\
>\text { Two-way communication }\end{array}$} \\
\hline \multirow[b]{2}{*}{ Visibility } & & $\begin{array}{l}\text { Understand } \\
\text { customer needs }\end{array}$ & & \\
\hline & & $\begin{array}{l}\text { and } \\
\text { motivations }\end{array}$ & \multirow[b]{2}{*}{ Give rise to } & \multirow{3}{*}{$\begin{array}{l}>\text { Brand-expression } \\
>\text { Encourage content creation } \\
>\text { Create enjoyable experience }\end{array}$} \\
\hline Editability & $\begin{array}{l}\text { Socialized } \\
\text { in }\end{array}$ & Promote & & \\
\hline \multirow{2}{*}{ Persistence } & & & \multirow[b]{2}{*}{ Give rise to } & \\
\hline & & $\begin{array}{l}\text { Motivate } \\
\text { cooperation }\end{array}$ & & $\begin{array}{l}>\text { Find influencer } \\
>\text { Construct networks }\end{array}$ \\
\hline
\end{tabular}

Fig. 2. Preliminary research model.

\section{Conclusion}

In this paper, we have presented the findings of our pilot study to explore the affordances of social media in engagement processes of an organisation and how those socialising affordances help organisations to increase engagement. We introduced social media and engagement related literature and adopted an affordances theoretical lens to guide the research. This study contributes to the understanding of social media and social media use in engagement processes [37, 38]. By basing our theoretical development on empirical data from this pilot study, we provide a more rigorous model for the next stages of our research. We attempted to answer how socialising affordances helps organisations increase engagement. The next stage of the research is for further investigation to validate our research model. Bryman and Bell [39] suggest in-depth interviews can help generate deep insights into the complex business environment. Therefore, our future stages involve in-depth interviews to validate our theoretical model. 


\section{References}

1. Noguti, V., Post language and user engagement in online content communities. European Journal of Marketing, 2016. 50(5/6): p. 695-723.

2. Ibrahim, N.F., X. Wang, and H. Bourne, Exploring the effect of user engagement in online brand communities: Evidence from Twitter. Computers in Human Behavior, 2017. 72: p. 321-338.

3. Brown, J., A.J. Broderick, and N. Lee, Word of mouth communication within online communities: Conceptualizing the online social network. Journal of interactive marketing, 2007. 21(3): p. 2-20.

4. Gensler, S., et al., Managing brands in the social media environment. Journal of interactive marketing, 2013. 27(4): p. 242-256.

5. Gallaugher, J. and S. Ransbotham, Social media and customer dialog management at Starbucks. MIS Quarterly Executive, 2010. 9(4): p. 197-212.

6. Hennig-Thurau, T., C. Wiertz, and F. Feldhaus, Does Twitter matter? The impact of microblogging word of mouth on consumers' adoption of new movies. Journal of the Academy of Marketing Science, 2015. 43(3): p. 375-394.

7. Mollen, A. and H. Wilson, Engagement, telepresence and interactivity in online consumer experience: Reconciling scholastic and managerial perspectives. Journal of business research, 2010. 63(9-10): p. 919-925.

8. Li, Y.-M., C.-H. Lin, and C.-Y. Lai, Identifying influential reviewers for word-of-mouth marketing. Electronic Commerce Research and Applications, 2010. 9(4): p. 294-304.

9. Hamilton, K. and M. Alexander, Organic community tourism: A cocreated approach. Annals of Tourism Research, 2013. 42: p. 169-190.

10. Gibson, J.J., The theory of affordances, in Perceiving, acting and knowing, R.E. Shaw and J. Bransford, Editors. 1977, Lawrence Erlbaum Associates: Hillsdale. p. 67-82.

11. Habibi, M.R., M. Laroche, and M.-O. Richard, The roles of brand community and community engagement in building brand trust on social media. Computers in Human Behavior, 2014. 37: p. 152-161.

12. Popp, B. and H. Woratschek, Introducing branded communities in sport for building strong brand relations in social media. Sport Management Review, 2016. 19(2): p. 183197.

13. Brownstein, M. Overreliance on social media will damage your brand. Adage 201017 July 2017]; Available from: http://adage.com/article/small-agency-diary/overreliancesocial-media-damage-brand/143779/

14. Hudson, S., et al., The influence of social media interactions on consumer-brand relationships: A three-country study of brand perceptions and marketing behaviors. International Journal of Research in Marketing, 2016. 33(1): p. 27-41.

15. Van Looy, A., Social media management. Springer Texts in Business and Economics. 2016, London: Springer.

16. Naaman, M., J. Boase, and C.-H. Lai. Is it really about me?: message content in social awareness streams. in Proceedings of the 2010 ACM conference on Computer supported cooperative work. 2010. New York: ACM.

17. Lovejoy, K. and G.D. Saxton, Information, community, and action: How nonprofit organizations use social media. Journal of Computer-Mediated Communication, 2012. 17(3): p. 337-353.

18. Harder, A., V. Howard, and D.R. Sedo, Creating Cohesive Community Through Shared ReadingA Case Study of One Book Nova Scotia. Partnership: The Canadian Journal of Library and Information Practice and Research, 2015. 10(1).

19. Hutchby, I., Technologies, texts and affordances. Sociology, 2001. 35(2): p. 441-456.

20. Zheng, Y. and A. Yu, Affordances of social media in collective action: the case of Free Lunch for Children in China. Information Systems Journal, 2016. 26(3): p. 289-313.

21. Markus, M.L. and M.S. Silver, A foundation for the study of IT effects: A new look at DeSanctis and Poole's concepts of structural features and spirit. Journal of the Association for Information systems, 2008. 9(10/11): p. 609-632.

22. Leonardi, P.M., When Flexible Routines Meet Flexible Technologies: Affordance, Constraint, and the Imbrication of Human and Material Agencies. MIS Quarterly, 2011. 35(1): p. 147-167.

23. Treem, J.W. and P.M. Leonardi, Social media use in organizations: Exploring the affordances of visibility, editability, persistence, and association. Annals of the International Communication Association, 2012. 36(1): p. 143-189.

24. Majchrzak, A. and M. Lynne Markus, Encyclopedia of management theory-Technology Affordances and Constraints Theory (of MIS). 2013, SAGE: Thousand Oaks. p. 832-836.

25. McKenna, B., M.D. Myers, and M. Newman, Social media in qualitative research: Challenges and recommendations. Information and Organization, 2017. 27(2): p. 87-99. 
26. Agostini, J.-M., The case for direct questions on reading habits. Journal of Advertising Research, June, 1964. 2: p. 28-33.

27. Porter, C.E., et al., How to foster and sustain engagement in virtual communities. California management review, 2011. 53(4): p. 80-110.

28. van Weezel, A. and C. Benavides, How to Engage the Audience? A Study on Using Twitter to Engage Newspaper Readers, in Handbook of Social Media Management, M. Friedrichsen and W. Mühl-Benninghaus, Editors. 2013, Springer: Berlin. p. 703-713.

29. Lin, J. and D. Ryaboy, Scaling big data mining infrastructure: the twitter experience. ACM SIGKDD Explorations Newsletter, 2013. 14(2): p. 6-19.

30. Tuten, T.L., Advertising 2.0: social media marketing in a web 2.0 world. 2008, London: Praeger.

31. Mangold, W.G. and D.J. Faulds, Social media: The new hybrid element of the promotion mix. Business horizons, 2009. 52(4): p. 357-365.

32. Vollmer, C. and G. Precourt, Always On: Advertising, Marketing, and Media in an Era of Consumer Control (Strategy+ Business). 2008, New York: McGraw-Hill.

33. Culnan, M.J., P.J. McHugh, and J.I. Zubillaga, How large US companies can use Twitter and other social media to gain business value. MIS Quarterly Executive, 2010. 9(4): p. 243-259.

34. Ashley, C. and T. Tuten, Creative strategies in social media marketing: An exploratory study of branded social content and consumer engagement. Psychology \& Marketing, 2015. 32(1): p. 15-27.

35. Gruzd, A. and C. Haythornthwaite, Enabling community through social media. Journal of medical Internet research, 2013. 15(10): p. 248

36. Gruzd, A., P. Mai, and A. Kampen, A how-to for using Netlytic to collect and analyze social media data: A case study of the use of Twitter during the 2014 Euromaidan Revolution in Ukraine, in The SAGE Handbook of Social Media Research Methods, L. Sloan and A. Quan-Haase, Editors. 2017, SAGE: Los Angeles. p. 513-529.

37. Wei, W., L. Miao, and Z.J. Huang, Customer engagement behaviors and hotel responses. International Journal of Hospitality Management, 2013. 33: p. 316-330.

38. Cabiddu, F., M. de Carlo, and G. Piccoli, Social media affordances: Enabling customer engagement. Annals of Tourism Research, 2014. 48: p. 175-192.

39. Bryman, A. and E. Bell, Business research methods. 2015, Oxford: Oxford University Press. 